\title{
Insect natural enemies as bioindicators in rice paddies
}

\author{
Takatoshi Ueno ${ }^{1} *$ \\ ${ }^{1}$ Institute of Biological Control, Faculty of Agriculture, Kyushu University, Hakozaki 6-10-1, Higashi-ku, Fukuoka City 812-8581, Japan
}

Received on 13 November 2012, revised on 10 December 2012, accepted on 10 December 2012

\begin{abstract}
In Asia, including Japan and Korea, rice paddies occupy the largest cultivated area in agricultural land. Rice paddies provide the habitats for many organisms including endemic species, sustaining high biodiversity. Insect natural enemies inhabiting rice paddies have an important function for rice production as agents of 'ecosystem services' because they play a major role in suppressing rice pests. The diversity and abundance of natural enemies can be a good index reflecting the 'healthiness' of agro-ecosystem services in rice paddies. The present study investigates whether insect natural enemies could be good biological indicators for general arthropod biodiversity and agricultural practice. First, the concept of ideal bio-indicators was summarized. The strategy to explore and select such bio-indicators was then proposed. Lastly, field survey was made to evaluate the abundance and biodiversity of natural enemies in Japanese rice paddies where chemical inputs, i.e., insecticide use, were different. The results showed that reduction of chemical inputs led to an increase in species richness or diversity of natural enemies including parasitoids and predators. Then, the data were analyzed to examine suitable indicator species to assess environmental soundness of agricultural practice and biodiversity in rice paddies. The density of several species of natural enemies did respond both to pesticide use and to general arthropod biodiversity. The analyses thus have indicated that natural enemies can be suitable as bio-indicators. Usefulness of indicator species in rice paddies is discussed in the context of ecologically sound agriculture.
\end{abstract}

Key words : Biodiversity, Environmentally sound agriculture, Indicator species, Ecosystem service

\section{Introduction}

Rice is the main food in Asia, including Japan and Korea. Many Asian countries traditionally use rice paddy systems in the production of rice. Rice paddies, together with the associated irrigation ponds, ditches and ridge, often constitute the traditional landscape in rural environments. Rice paddies commonly occupy the largest cultivated area among agricultural land, and form an ecosystem representing a major seminatural environment. Rice-based ecosystems are therefore a key ecosystem in rural environments of Asia.

Rice paddies provide the habitats for many organisms; such organisms inhabiting rice paddies constitute a 'community', which contains a wide variety of species that differ in their functions and represents biological diversity in agricultural lands (Yano, 2002; Kiritani,

\footnotetext{
*Corresponding author: Tel: +누락

E-mail address: ueno@grt.kyushu-u.ac.jp
}

2009). This means that rice paddies support, at least in part, biodiversity in the area or region. In addition, rice paddies are filled with water and hence functions as a wetland habitat for species that are endangered nowadays because of the loss of wetlands in lowland areas (Amano, 2009; King et al., 2010).

Recently, biodiversity in agricultural land has received growing attention because it plays a significant role in agro-ecosystem function (Dudley et al., 2005; Javis et al., 2007). For example, rice paddies are the habitats for diverse parasitoids and arthropod predators, which are important natural enemies of rice pests (Ueno, Yano, 2002; 2010). Such beneficial organisms serve agro-ecosystem function regulating pest populations (Barbosa, 1998; Hajek, 2004). In agricultural fields where pesticide use is minimized, crop production commonly depends on natural control provided by natural enemies because they have an important role in regulating pest populations (Barbosa, 1998; Hajek, 
2004; Ueno, 2010). Their importance is particularly highlighted when the resurgence of pests takes place (Pimentel, 1997; Dent, 2000). Indiscriminate use of agro-chemicals such as insecticides harms natural enemies and causes the loss of biodiversity of such beneficial organisms.

In Japan, being 'ecological' is on strong demand in agriculture nowadays. Sustainable management of rice paddies and the surrounding environment is also an increasing concern in the country. Large-scale use of agro-chemicals cannot be an option of farming practices due to public concern for environment and health issues. However, so called ecologically or environmentally sound farming is mostly desired in terms of the production of safe food for humans with minimum use of agro-chemicals. Its impact on conservation of biodiversity is often neglected or overlooked. Hence, the consequent impact of the so-called eco-friendly farming on organisms is usually unclear. It is thus expected that use of indicator organisms can provide the public concern to reconsider what is truly 'ecological' and the so-called eco-friendly farming from the viewpoint of biodiversity conservation.

Environmentally sound rice production should now be linked to biodiversity in order to meet recently growing demand that organism communities in rural environments should be conserved as possible though this idea has many conflicting aspects. Because the biodiversity of beneficial natural enemies is a key resource to improve the productivity and sustainability in rice paddies, conservation of natural enemy diversity should be an important approach for sustainable rice production. By focusing the impact on biodiversity, eco-friendly rice paddy farming would meet the demand by consumers (i.e. safe food) as well as the demand from a point of view of sustainable production.

Conserving biodiversity in rice paddies and rural areas may be a formidable challenge. Use of insecticides dramatically reduces the incidence of rice pests and the yield loss, and herbicides allow reducing labor required for weed control (Pimentel, 1997; Dent, 2000). While the intensification of rice production systems results in the yield higher and the price of rice lower, it should make rice paddies poor in biodiversity and lessen capability of ecosystem service (Kruess and Tscharntke, 1994; Crowder et al.,2010; Jarvis et al., 2007; 2010). However, biodiversity conservation through reduction of agrochemical use would decrease labor productivity of rice.

Nevertheless, studies have demonstrated that biodiversity conservation can help sustainable use of rice paddies and can reduce the incidence of pest outbreaks (Kruess and Tscharntke, 1994; Bianchi et al., 2006; Corwder et al., 2010). Agro-biodiversity performs a number of ecosystem services (Dudely et al., 2005; Jarvis et al., 2007). For example, natural enemies such as insect parasitoids and predators provide control of pest species in agro-ecosystems (Barbosa, 1998; Hajek, 2004), and this is also the case in rice paddies (Ueno, 2010; Ueno, 2012). Importantly, recent studies have demonstrated that the presence of diverse species of natural enemies can enhance the control of pest populations through their complementary function (Kruess and Tscharntke, 1994; Bianchi et al., 2006; Crowder et al., 2010). Thus, conservation of the community of natural enemies in rice paddies would contribute to sustainable rice production through stable pest control function (Ueno, 2010; Ueno, 2012).

Biodiversity in rice paddies and the adjacent environment is fairly rich; more than 5000 species are recorded from rice paddy ecosystems in Japan (Kiritani, 2009). More than 100 species of arthropods can be recorded even from a paddy field. In addition, there are many species that only specialists for taxonomy can identify to the species level. Thus, indicators that properly reflect biological diversity is needed because the evaluation of biodiversity in its entirety is not be practical (McGeoch, 1998; Buchs, 2003). Use of biological indicators or indicator organisms is ideal.

The main topic then is to select ideal indicators. 
Indicator species should reflect abiotic or biotic state of an environment, indirectly reflecting biodiversity of at least some groups of animals, arthropods and plants within an agricultural land. Although a diverse kind of organisms such as plants, animals, insects and microorganisms occur within an ecosystem or an agricultural field, several studies have shown that arthropods are among good candidates of biological indicators (McGeoch, 1998; Maleque et al., 2009; Lewandowski et al., 2010). Arthropods include insects and spiders that are commonly found in rice paddies. Insects and spiders can be suitable indicators because (1) they are small with a short generation time and (2) they are sensitive to change in local abiotic and biotic conditions (McGeoch, 1998; Maleque et al., 2009; Lewandowski et al., 2010). These features enable them to respond to an environmental change by quick migration and population increase. Thus, arthropods like insects and spiders are flexible and timely organisms reflecting the current status of 'environment'.

There are several requirements for ideal indicator organisms (McGeoch, 1998; Buchs, 2003). First, indicator species should reflect both the level of biodiversity and the intensification of farming practices, in order to link between biodiversity and agriculture. Second, indicators should be easily recognized and monitored. Species that are too small and difficult to recognize are clearly not suitable for indicators. Also, species that are difficult to identify to species or group level should be avoided.

Third, indicator species should not be too scarce; 'rare' or endangered species are often highlighted in the study of biological conservation (Ueno, 2010). It is however not ideal to use such rare species because such species are likely to be detected with very low frequency or even undetected. The incidence of rare species may be a good indication that the rice paddy should be preserved in terms of the species conservation but lack of such species would rather be common in many rice paddies with environmentally friendly practices. Politically and practically, it is ideal to select species that are rather common and familiar to people. In addition, detailed studies are only possible if the species are easily reared. Although there may be no perfect indicators, at several prerequisite mentioned above should be satisfied as indicator organisms. In particular, the first requirement would be important upon selecting indicators.

Indicator organisms are useful for linking between biodiversity and environmentally sound practices. Also, indicators are useful for: (1) linking between farmers and biodiversity and (2) linking between farmers and consumers. By using organisms that are easy to recognize, farmers and consumers themselves can monitor the incidence and abundance of indicators. Self-monitoring by farmers are recommended because it facilitates the decision-making by the farmers to use or not to use agrochemicals such as insecticides, to choose or not to choose selective insecticides and to apply or not to apply other practices that are friendly to indicator organisms. Indicator organisms should also improve and promote 'awareness' to environment and biodiversity, which would lead to increase motivation and action for environmentally sound farming.

Use of indicator species will contribute to sustainable development of rice production because indicator organisms allow the quantitative assessment of environmental soundness of agricultural practices. In addition, farming plans or practices to conserve and increase indicator organisms can enhance biodiversity in its entirety of rice paddies because such plans or practices would have side effects that lead to enhancement of whole biodiversity in rice paddies and the surrounding environment. Plans to conserve some indicator organisms should create environmental conditions that enhance biodiversity associated with the indicators. Non-associated biodiversity would also be improved because many organisms should share similar conditions to inhabit. It is not clear but likely that any single indicator species cannot reflect all 
aspects of biodiversity in an area (McGeoch, 1998). Therefore, use of multiple indicator species may be a better approach though there may be no perfect indicators that reflect the richness of all taxon (Lawton et al., 1998).

It is ideal to select organisms that are clearly beneficial to agricultural production (Ueno, 2010; Ueno, 2012). Neutral species may be selected as indicators if they reflect both biodiversity and environmental soundness. However, it is politically and practically ideal if the candidates of indicators are beneficial organisms in agriculture because it is much easier to convince farmers why the conservation of indicators is important and why indicators are useful for the farmers. Farmers would benefit from conserving natural enemies that help reducing pest damage (Pimentel, 1997; Barbosa, 1998; Crowder et al., 2010), which, in tern, allows reducing pesticide use. Also, the incidence and abundance of a species should correlate with richness of specialist natural enemies. The presence of diverse species, regardless of their ecological function (e.g., pests, neutral species, or natural enemies themselves), would increase richness of generalist natural enemies. Natural enemies are therefore likely to reflect both biodiversity and environment.

Accordingly, I have been studying the diversity of natural enemies in rice paddies to explore candidates of indicator organisms from natural enemies inhabiting rice paddies, and to assess whether indicator natural enemies can be use for conservation planning in rice paddies. Although biodiversity refers to all species including plants, animals, insects and microorganisms occurring within an ecosystem, here, I mainly focus on arthropod diversity in the present study because they occupy the vast majority of the number of individuals and species detected in rice paddies at above-ground level (Kiritani, 2009; Ueno, 2010) and also because of the reasons mentioned above. In the present paper I give part of the on-going study and show that indicator natural enemies can allow the quantitative assessment of environmental soundness in rice paddy farming. Use of indicator species will contribute to sustainable development of rice production.

\section{Materials and Methods}

\section{Field Survey}

Biodiversity in rice paddies was surveyed in the present study. Field survey was conducted i on relatively small-scale farms between 2008 and 2009 . Study sites are located at Nijyo-machi Town, Fukouoka Prefecture, a lowland area in northern Kyushu main island of Japan. Rice variety chosen for the survey was Hinohikari, which is the most popular variety in northern Kyushu. In Kyushu, rice was an annual crop, and the variety Hinohikari was transplanted from late June to early July. Harvest was mostly in early October. Rice paddies selected for the present survey included both organic farming fields and conventional farmer's fields. In conventional fields, farmers exclusively used Imidacloprid, a systemic insecticide acting as an insect neurotoxin, during the seeding stage before transplanting as the chemical control tool to manage insect pests. In many fields (but not all the fields), herbicides were applied once after transplanting rice. Around the flowering stage of rice, farmers applied Dinotefuran (a systemic insecticide) twice to control leafhoppers, planthoppers and green bugs but not all farmers applied such insecticides during the growing stage of rice. Thus, rice paddies studied were placed in three types; (1) organic fields (without any pesticide), and (2) fields with insecticides only once during the seeding stage or (3) three times (once in seedling and twice during growing stages). In my study, I mainly focused on maturing stage of rice because all chemical inputs were terminated in this growth stage, which was suitable for the purpose of the study. The maturing stage of Hinohikari was between September and 
October.

Arthropod natural enemies were sampled in 40 farmer's fields. To assess the cumulative effect of pesticide use, sampling was undertaken between September and October when more than 2 weeks had been passed since the final application of pesticides. In 2008 and 2009, general survey was first made to know the species composition of natural enemies found in the area of Nijyo-machi Town. For this purpose, sweeping with an insect net and visual collection were performed to obtain specimens, and the list of natural enemies was prepared. In 2009, data collection for analyzing biodiversity and exploring candidate organism were also made. To do this, inspection of the entire plant was made to search natural enemies to obtain the data. Sampling was made by walking $5 \mathrm{~m}$ along 3 lows of rice plants. Each field was sampled at two sites. This sampling was repeated twice in different days for each field. The numbers of natural enemies were counted, and the species were recorded. When necessary, specimens were collected for exact identification to species. The results reported here were based on the data collected from September to October, 2009.

\section{Data Analyses}

The data were analyzed with the aid of JMP (SAS, 2008). In my study, the diversity of natural enemies, i.e., parasitoids and predators, was estimated by Shannon's Index (= Shannon-Wiener Index), which allows the measurement of biodiversity. This index is commonly used because it has an advantage to take into account the number of species and the evenness of the species, both of which are important concept of biodiversity.

\section{Results and Discussion}

First, the effect of insecticide applications on species richness of natural enemies was examined. For this purpose, natural enemies were divided into two main categories based on their basic function; parasitoids and predators. The relationship between insecticide input and diversity index (recorded per $5 \mathrm{~m}$ in 3 lows) of natural enemies was then assessed with a generalized linear model (GLM). Overall, species richness and biodiversity increased with a reduction of insecticide use. Insecticide use significantly influenced the species richness (GLM; link function for poisson; $\mathrm{df}=3, x^{2}=$ 18.5, $\mathrm{P}=0.0004$ for parasitoids; $\mathrm{df}=3, x^{2}=21.8, \mathrm{p}$ $<0.0001$ for predators). As expected, the highest levels of species richness for parasitoids (Fig. 1a) and predators (Fig. 1b) were observed in rice paddies where no insecticides had been used. It is well known that rice paddies provide habitats for many organisms, including beneficial natural enemies that are important resources for natural control of pest organisms (Kiritani, 2009; Yano, 2002; Ueno, 2010). However, a number of practices used in modern rice production systems can harm such beneficial species, weakening the function of natural biological control. The present study has demonstrated that insecticide use decrease the diversity of natural enemies in commercial rice paddies.

Second, feasibility of natural enemies as indicator organisms was examined. Here, Itoplectis naranyae Ashmead (Hymenoptera: Ichneumonidae) was selected for the following assessment as a potential candidate. Itoplectis naranyae is a solitary parasitoid wasp and has a wide biogeographic range in Asia, distributing among Japan, China, Formosa, Korea, Philippines, etc. (Yasumatsu and Watanabe, 1965; Momoi, 1966). This parasitoid attacks pupae of lepidopteran pests of rice, including the rice leaf folder Cnaphalocrocis medinalis Guenée (Townes et al., 1965; Yasumatsu and Watanabe, 1965); the percentage of parasitism by $I$. naranyae occasionally exceeds $50 \%$ of pupae of the rice leaf folder in autumn. Itoplectis naranyae therefore is an important natural enemy of the rice leaf folder. However, information is lacking on how common I. naranyae is in 


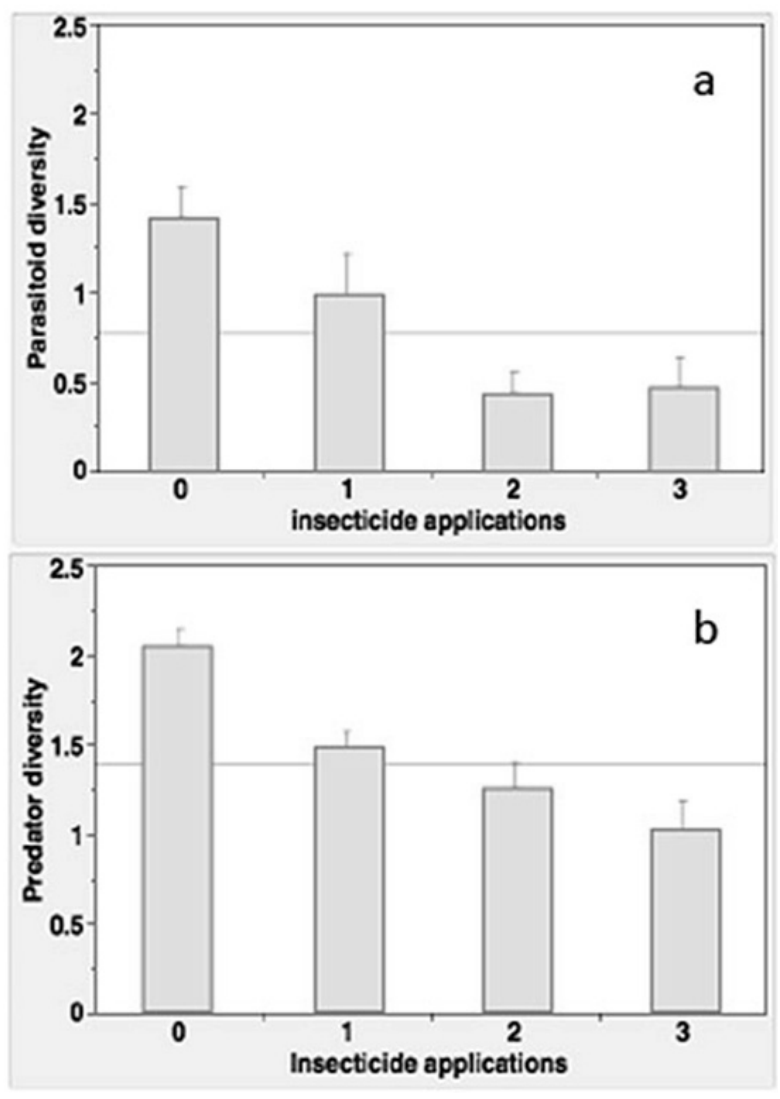

Fig. 1. Relationship between insecticide applications (total number of applications during the growing season) and diversity of natural enemies measured with Shannon's index (above: parasitoids, below: predators).

rice paddies and how its abundance is affected by pesticide use. Previous records suggest that this parasitoid wasp is widely distributed in rice paddies in Japan and is a fairly common species. In addition, among parasitoids known from rice paddies, I. naranyae is readily recognized because of its size and body color and is easily mass - reared in the laboratory (Ueno and Tanaka, 1994; Ueno, 1999). Taken together, this parasitoid wasp can be a good candidate of indicator organisms among natural enemies. Hereafter, the analyses were made to evaluate whether $I$. naranyae could be suitable as an indicator natural enemy.

I. naranyae was detected in 28 out of 40 rice paddies (70.0\%). The probability of its incidence was significantly related to pesticide use (Fig. 2; chi-squared test; $\mathrm{p}=0.032$ ); it was $100 \%$ in organic fields while only $33 \%$ of paddy fields with 3 times insecticide- applications

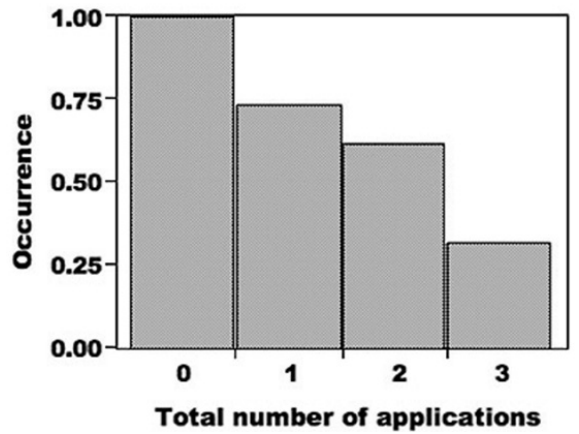

Fig. 2. Relationship between insecticide application and the occurrence ( $=$ incidence) of Itoplectis naranyae in farmers' rice paddies.

supported the parasitoid. The abundance of I. naranyae, i.e., the mean number per field, differed significantly among rice paddies differing in insecticide applications (Fig. 3; GLM, $\mathrm{p}=0.018$ ). Rice leafroller $C$. medinalis was detected in all 40 rice fields, indicating that this pest widely occurred in the study area.

Rice leafroller $C$. medinalis is a major pest of rice in many Asian countries (Bautista et al., 1984; Padmavathi et al., 2012). Although control of $C$. medinalis with chemicals is not difficult (Endo et al., 1987), its occurrence was widespread because many farmers try to reduce the number of insecticide applications as possible due to public concern and the cost of the chemicals. Under this situation, it is ideal if the parasitoid complex of $C$. medinalis can play a significant role in suppressing this pest (Ueno, 1999). Farmers may benefit from protecting I. naranyae by reducing insecticide applications. Although reduction of insecticide use increases the density of rice leaf roller, the presence of parasitoids can keep the pest density to the below-economically injurious level (though the overall density of the pest will increase).

The present study has demonstrated that I. naranyae occurs widely and is very common in rice paddies (Fig. 2). The density of the parasitoid is related to insecticide inputs (Fig. 3), indicating that I. naranyae is sensitive to chemical use. Alternatively, such a relationship may arise because its host is fewer in rice fields with higher inputs of insecticides. In any case, the presence 


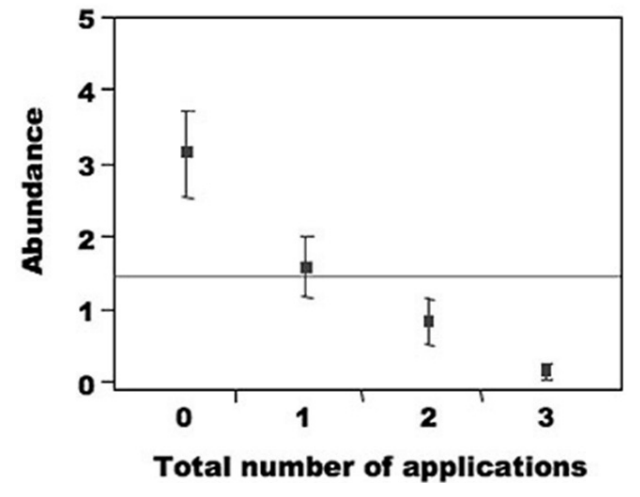

Fig. 3. Relationship between insecticide application and density of Itoplectis naranyae in farmers' rice paddies.

and abundance of $I$. naranyae can reflect the extent of insecticide use, a major measure for environmental soundness of farming practice.

I. naranyae is readily recognized because it is relatively size and has a conspicuous body color; this species is one of the easiest parasitoids to recognize and identify among parasitoids recorded from rice paddies (Ueno, 1999). My unpublished data also have demonstrated that the ichneumonid parasitoid $I$. naranyae reflected overall arthropod diversity. Taken together, I. naranyae is a good ecological indicator of the environment of rice paddies and may be used as a bioindicator to examine whether natural enemies are preserved in rice paddies or to assess whether pesticide use is minimized.

In recent years, chemical inputs have been largely reduced in rice production of Japan; in fact, the count of pesticide use was only three times at maximum in the study area, and the used insecticides did not have broad spectrum. Nevertheless, the present results have given evidence that pesticide use harms beneficial natural enemies like $I$. naranyae. Insecticide use can thus cause the loss of biodiversity of natural enemies and should weaken the function of agro-ecosystem service. Reduction of insecticide use as possible would help conserving the community of natural enemies, allowing the avoidance of disruption of native ecosystems and agro-ecosystems. However, in the future study, we need to examine what extent we can reduce agrochemical use by considering the balance between rice production and biodiversity conservation.

Environmentally sound agriculture, which is often desired in terms of the production of safe food for humans, should be linked to the conservation of biodiversity by minimizing use of agrochemicals and other practices potentially harming the environments. The present study has demonstrated that natural enemies can be useful to assess what extent a given practice is friendly to the environment, on the basis of the diversity of natural enemies and the abundance of particular natural enemy species. Because monitoring biodiversity is time and labor consuming, it is ideal to select indicator species that reflect both the level of biodiversity and environmentally sound practices. Some natural enemies can be suitable for indicator species (Maleque et al., 2009; Ueno, 2010) as shown in the present study with $I$. naranyae.

There are a number of subjects that should be focused in the future study. The enhancement of biodiversity in rice paddies would depend on biodiversity of the surrounding environment; after transplanting rice, many organisms including pests, natural enemies and neutral species immigrate to colonize rice paddies from the surrounding environment. It is therefore crucial to highlight the importance of the surrounding environment such as ridge and vegetation areas around rice paddies. The extension of urbanized areas causes a rapid change of rural areas, resulting in a decrease of vegetation around the areas. Also, urbanization causes fragmentation of the habitats. Habitat fragmentation and loss of vegetation area are both important factors leading to a decrease of biodiversity and a reduction of the power of natural control (Bianchi et al., 2006; Kruess and Tscharntke, 1994).

It is well documented that inappropriate use of insecticides can increase the incidence of outbreak of some pests (Pimentel, 1997; Dent, 2000). Control of pests by natural enemies is a biological process (Barbosa, 1998; Hajek, 2004), and such natural bio- 
logical control depends on maintenance of biodiversity of natural enemies (Kruess and Tscharntke, 1994; Bianchi et al., 2006; Crowder et al., 2010). The diversity of natural enemies can be lost by improper use of agrochemicals and simplification of agro-landscape, incurring considerable economic and environmental costs (Kruess and Tscharntke, 1994; Pimentel, 1997; Dent, 2000; Bianchi et al., 2006; Crowder et al., 2010). Thus, better understanding of the function of natural enemies in the context of host-parasitoid or prey-predator interactions is required.

Reduction of insecticide use evidently increases the abundance of each natural enemy species but also the diversity of natural enemies. The change should be mediated by two biological processes; a reduction of direct harmful effect of chemicals to natural enemies and an increase of indirect positive effect through an increase of host or prey density on natural enemies. Factors impacting the diversity and abundance of natural enemies should also be addressed in future study. Finally, the ecological or biological relationship between indicator species and community structure or biodiversity is not clear, however. These are also future subjects in rice paddy ecosystems.

In summary, it is possible to select indicator natural enemies that are ideal for assessing both overall biodiversity and environmental soundness of farming practices. Conservation of indicator natural enemies should promote ecosystem function such as pest regulation. Such indicator organisms can be used in the design and evaluation of sustainable farming systems in rice paddies. Although public concern has been growing, the concern about agro-biodiversity seems not to be high enough. Policy to positively use indicator organisms to facilitate environmentally sound rice production would stimulate the public concern and awareness of both environment and biodiversity. Further data should be accumulated to establish scientific basis for evaluating the effectiveness of indicators and making the guidelines of using bio-indicators.

\section{References}

Amano T. 2009. Conserving bird species in Japanese farmland: Past achievements and future challenges. Biological Conservation 142:1913-1921.

Barbosa P. 1998. Conservation Biological Control. San Diego, Academic Press.

Bautista RC, Heinrichs EA, Rejesus, RS. 1984. Economic injury levels for the rice leaffolder Cnaphalocrocis medinalis (Lepidoptera: Pyralidae): Insect infestation and artificial leaf removal. Environmental Entomology 13:439-443.

Bianchi FJJ, Booij CJH, Tscharntk T. 2006. Sustainable pest regulation in agricultural landscapes: a review on landscape composition, biodiversity, and natural pest control. Proceedings of the Royal Society B; Biolgical Sciences 273:1715-1727.

Büchs W. 2003. Biotic indicators for biodiversity and sustainable agriculture - introduction and background. Agricultrue, Ecosystem \& Environment 98:1-16.

Crowder DW, Northfield TD, Strand MR, Snyder WE. 2010. Organic agriculture promotes evenness and natural pest control. Nature 466:109-112.

Dent D. 2000. Insect Pest Management $2^{\text {nd }}$ ed. London, Cabi Publishing.

Dudley N, Baldock D, Nasi R, Stolton S. 2005. Measuring biodiversity and sustainable management in forests and agricultural landscapes. Phylosophical Transactions of the Royal Society B; Biological Sciences 360:457-47.

Endo S, Kazano H, Masuda T. 1987. Insecticide susceptibility of the rice leafrooler larvae, Cnaphalocrocis medinalis Guenee (Lepidoptera: Pyralidae). Applied Entomology and Zoology 22:145-152.

Hajek A. 2004. Natural Enemies: An Introduction to Biological Control. Cambridge, Cambridge Univ. Press.

Jarvis DI, Padoch C, Cooper HD. 2007. Managing Biodiversity in Agricultural Ecosystems. New York, Columbia University Press.

King S, Elphick CS, Guadagnin D, Taft O, Amano T. 2010. Effects of landscape features on waterbird use of rice fields. Waterbirds 33:151-159.

Kiritani K. 2009. A Comprehensive List of Organisms Associated with Paddy Ecosystems in Japan. Saga, Daido Printing Co. Ltd.

Kruess A, Tscharntke, T. 1994. Habitat fragmentation, species loss and biological-control. Science 264: 1581-1584.

Lawton JH, Bignell DE, Bolton B, Bloemers GF, Eggleton P, Hodda M, Holt RD, Larsen TB, Mawdsley NA, Stork NE, Srivastava DS, Watt AD. 1998. Biodiversity inventories, indicator taxa and effects of habitat modification in tropical forest. Nature 391:72-76.

Lewandowski AS, Noss RF, Parsons DR. 2010. The effectiveness 
of surrogate taxa for the representation of biodiversity. Conservation Biology 24:1367-1377.

Maleque MA, Maeto K, Ishii HT. 2009. Arthropods as bioindicators of sustainable forest management, with a focus on plantation forests. Applied Entomology and Zoology 44: 1-11.

McGeoch MA. 1998. The selection, testing and application of terrestrial insects as bioindicators. Biological Reviews 73 : 181-201.

Momoi S. 1966. Ichneumonidae (Hymenoptera) collected in paddy fields of the Orient with descriptions of new species. Mushi, 40:1-11.

Padmavathi CH, Katti G, Padmakumari AP, Voleti SR, Subba Rao LV. 2012. The effect of leaffolder Cnaphalocrocis medinalis (Guenee) [Lepdoptera: Pyralidae] injury on the plant physiology and yield loss in rice. Journal of Applied Entomology. In press.

Pimentel D. 1997. Techniques for Reducing Pesticide Use: Economic and Environmental Benefits. Chichester, John Wiley and Sons.

Townes H, Momoi S, Townes M. 1965. A Catalogue and
Reclassification of the Eastern Palearctic Ichneumonidae. Memoirs of the American Entomological Institute No. 5.

Ueno T, Tanaka T. 1994. Comparative biology of six polyphagous solitary pupal endoparasitoids (Hymenoptera: Ichneumonidae): differential host suitability and sex allocation. Annual Entomology Society of America 87:592-598.

Ueno T. 1999. On major ichneumonid parasitoids in cultivated fields: their role and practical use. Plant Protection 53: 85-88.

Ueno T. 2010. Biodiversity in rice paddies and use of indicator species to assess environmental friendship of agricultural practices. International AFAS Joint Symposium Between Korea and Japan. 7:126-132.

Ueno T. 2012. Environmentally sound agro-practice, biodiversity and indicator species in rice paddies. EEBS, in press.

Yano K. 2002. Insect Fauna in Paddy Field. Tokyo, Tokai Univ. Press [in Japanese].

Yasumatsu K, Watanabe, C. 1965. A Tentative Catalogue of Insect Natural Enemies of Injurious Insects in Japan. Part 2. Host Parasite-Predator Catalogue. Fukuoka, Entomol. Lab., Fac. Agric., Kyushu Univ. Press. 